\section{THEORY OF MENSTRUATION.}

\section{To the Editor of The Lancer.}

DEAR Sir,-The accompanying practical observations and judicious comments of $\mathrm{my}$ acute friend, $\mathrm{Mr}$. Girdwood, relate to a sub. ject so important in reference both to physiology and to medical jurisprudence, and contain so just and candid a tribute to the ingenious though neglected researches of a late distinguished practitioner of this Metropolis, that I feel assured you will, with me, consider them as worthy of being submitted to the profession through the medium of your valuable Journal.

This communication has been drawn up by Mr. Girdwood, at my solicitation, and the beautiful theory established by Dr. Power, and here so ably illustrated, is in harmony with all the best-established facts in comparative anatomy, though at variance with the crude and contradictory opinions so generally entertained on this subject.

I have only to add that the cases and views here detailed by Mr. Girdwood, were fully announced to me by that gentleman, and repeatedly discussed between us, as early as 1836, when he was not aware of the extent to which the important results of his experience had been anticipated by previous observers, and at which period I solicited him to direct the attention of physiologists to these most interesting facts. I remain, dear Sir, your obedient servant,

Robert E, Grant.

Seymour-place North, Euston-square, Feb. 20, 1843.

My dear Sir,-I at length comply with your urgent request, and place before you my inquiries on the subject so often mentioned to you in 1836 , viz., the exact correspondence in the number of cicatrices found on the ovaries of females with the number of times they have menstruated, and on the probable dependance of that periodical discharge on the descent of ovules through the Fallopian tubes; and, in illustration of my views, I now send for your inspection the ovaries of a young unmarried lady who died a few days ago, and who was sixteen years and ten months old at the time of ber decease. Ten months ago her fatal malady commenced, and at the same time she ceased to menstruate. The catamenia first appeared when between twelve and thirteen; they were regular in their appearance during the three years they continued to occur. Thus, she had about six and thirty periodic returns. On examining these ovaries you will observe that the surface presents several indentations, some isolated, some grouped together and incident upon each other. These indentations, or small cicatrices, are about the size of a mustard-seed; they are oblong in form. Those in groups have the oblong shape less

No. 1018, evident than those which are isolated, and are altogether not so well defined; but still, without much difficulty, the eye can detect spot after spot in each group, and single out almost every constituent indentation. In all I think from thirty-two to thirty-four of these marks may be reckoned, - about eighteen in one and about sixteen in the other ovary.

To explain the causes of these appearances let us place a series of facts in consecutive relation to each other.

The ovary of a female who has never menstruated is a soft pulpy mass, oval in shape, with a regularly defined outline, and possesses a smooth, polished, glistening surface.

In a female who has menstruated e. g. for ten years, and whose second lustrum of menstruation has thus passed, the external characters of the ovary have much changed. The soft, glistening, polished surface is now seamed and scarred throughout; its regular oval form no longer exists; deep corrugations have destroyed it; scars, some still isolated, appear, but a mass of cicatrices, irregular and ill-defined, generally marks the surface.

The ovary of a female approaching anility, who has ceased to indicate, by the usual periodic secretions, her capability for fecundation, has lost entirely its regular rotundity and plumpness, and instead of a soft, pulpy, glistening substance, it is a grisly, withered, corrugated mass.

Examples, in illustration of these facts, are easily produced. I wave, however, all others excepting those $I$ am desirous of placing before you as indicating, in my opinion, that those indentations on the surface of the ovary are correlative in number with the periods of menstruation, and that the menstrual discharge is a secretion excited by the presence of an ovum in the ovary at its full period of development, and in the act of disengagement from it and transmission through the Fallopian tube.

Before relating these, let me observe that small vesicular ovules exist in great numbers in the stroma or parenchyma of the ovary; that they may be seen there in different stages of development; that some, far in advance of others, are so increased in size, that even in the ovary of a six months' foetus they are evident without the use of a lens. ${ }^{*}$ As the female approaches puberty, some one of the ovules becomes more and more developed, approaches the surface, and, as in the instance $I$ am now going to relate, it occasions a transparency of some degree over this small Graatian vesicle.

In June, 1834, a whole family were ill of scarlet fever, under the care of Mr. Richard. son, of Bayswater, and myself. A girl, be-

* These were distinctly seen by me in a six months' foetus of a pregnant weman who drowned herself in Paddington canal in 1834, 
ween eight and nine years, succumbed to much pain in the pelvis, she menstruated, the disease. In her the ovaries presented this being the first and only time she had the usual polished, glistening surface of ever had that secretion. I opened the body those of a female that had not menstruated. this morning. The ovaries were plump and A spot, however, on the left ovary was dis- rather larger than usual, soft to the touch, tinctly perceptible, and arrested attention; and glistening. There were here and there it was to some extent transparent, slightly diaphanous specks, caused by the absorption elovated, and surrounded by a net-work of or thinness of the peritoneal coat, and the injected capillaries. On cutting open this approach to the surface of the Graafian vesiovary the transparency and elevation were cles. There was no mark or scar whatever found to be owing to one of these vesicles, on the right ovary; but on the left, abont very much enlarged, and iudeed now projecting immediately under the peritoneum.

Had this girl lived and reached puberty, what would have happened in respect to this vesicle? I have no doubt that it would have escaped from the ovary, passed through the Fallopian tube and uterus, and that this phenomenon would have been coexisteut with the first period of menstruation; and had she died immediately after or during the act of this first menstrual secretion, appearances similar to what $I$ have now to notice would undoubtedly have been found.

In December, 1832, Ann Davies died of scarlet ferer, under the care of Mr. Webster, surgeon, of Connaught-terrace, and myself. The menstrual flux made its appearance six hours before dissolution. On the left ovary there was an oval cavity, large enough to admit a tare, and no doubt left by the recent escape of an ovule; its margin was unequal and floccular, and, as well as the walls throughout, of a deep.red colour. This female had menstruated for years, and the appearnces which I consider as the usual indications of frequent menstruation, as already described, were evident on the surface of the ovaries.

The ovaries and the uterus of this female were carefully removed from the body, and the day after our examination were presented to Dr. Robert Lee, to whom I repeated (what 1 had previously communicated to him) my views on this and similar appearances, as detailed in this communication, but $I$ could not then induce that distin. guished pathologist to adopt my views.*

In my case-book I find, under the date of May 23, 1835, the following memoranda :"Emma Bull died yesterday, dropsical, the result of diseased heart and lungs. Two years ago, during an attack of asthma, after

* In The Lancer of June 29, 1839, is given the account of a meeting of the MedicoChirurgical Society, at which a paper by Dr. Lee was read, on the corpus luteum, and when Mr. Solly mentioned that in a young. Iady who had died shortly after her menstrual period, and of whose chastity there could be no dubt, there existed appearances of a nature similar to those in this case, and which were perfectly in accordance with the views I have developed. The expression used is that "an enormons corpus luteum was discovered." the centre of the posterior surface, there existed a reddish part, about the size of a mustard-seed, which had quite the appearance of an ulceration skinned over. The uterus and its appendages are in the possession of Mr. Webster."

During the same year a young woman also died under my care. She had men. struated three times. The surface of one ovary presented two cicatrices; that of the other, one similar to that described in the last case.

In January, 1834, Jane Cumming, eighteen years of age, died of consumption. She had menstruated only six times. Mr. Webster, who was aware of my views regarding the exciting cause of menstruation, and of my anxiety to examine the ovaries, allowed me to be present at the autopsy. We could readily detect five depressions or cicatrices, three on one, two on the other ovary; of a six th we were doubtful.

In August, 1838, I opened the body of Miss G., who had not completed her sixteenth year, and who had been regular for two years previous to her sudden death. In her I found about twenty-two of the usual marks on the ovaries. All these appearances, as they occurred in these different cases, were brought under the notice of my friend Dr. Robert Lee, but still without being able to convince him that the views I entertained respecting their cause, as above explained, were correct.*

I might extend my communication by cases of a character similar to those $I$ have related, and which were accompanied by similar results. Enough, however, I hope has been stated to establish an opinion expressed to you in the session of 1836-37,

* Indeed, I cannot find that in his frequent published communications Dr. Lee takes any notice of these cicatrices until last year, when I perceive in his lectures he incidentally alludes to them. Mentioning the case Sir A. Cooper sent him, and those I showed him, he adds, that he "was not then aware that cicatrices are never present on the surface of the ovaria before menstruation has commenced." This is quite true, for although I had seen cases often enough to satisfy myself of the truth of my views, the cases related in this letier were the first of so decided a character, which it was in my power to offer for the conviction of others. 
when I, as now, attended your lectures, and enjoyed an hour's emancipation daily from my professional fatigues.

Well do I recollect your scepticism on this matter, and of my comparison of a woman to a domestic hen,' another biped; but the woman, instead of, like the bird, depositing her egg daily for some indefinite period, only takes more time to mature it, and requires a more tedious and complicated process to void it only once a month.

What? I hear it asked, Are we to credit in our own species the fart of a female passing eggs every few weeks for twenty or thirty years? The statcments $I$ have made above, however, are of facts, and such as are capable of easy corroboration. Nor, indeed, is there anything wonderful in a female passing periodically these numerous eggs, as asserted. Let her be supposed to continue for twenty or thirty years in this fecundative condition, with her ovaries performing regularly their functions, there would have been, even then, only from two hundred and forty to three hundred and six ty ova passed; and, tracing the state of these organs from their soft pulpy condition previous to puberty, through the regular changes they undergo as the woman advances in years, up to the withered, shrivelled, corrugated form they present when anility arrives,-is it too much to conceive that each ovary may have had from one hundred and twenty to one hundred and eighty times its surface opened for the escape of so many ovules?

At all events I repeat the fact, now attested by my numerous observations, that there exists a most close and remarkable relation between the number of cicatrices on the surface of the ovaries and the number of times a female has menstruated.

The question which, in this communication, I have attempted to solve, has been of late much obscured by the circumstance of those who have attempted its solution limiting their attention to the development of the human ovum alone. From the perfect innocence of comparative anatomy enjoyed by most modern writers on the subject, and by their professional avocations, guided to appearances in the human uterus and ovaries alone, their inquiries have been unfortunately limited to the investigation of human generation only, and thus, by being confined to this limited sphere of observation, and from their position taking, as it were, a monocular view of the matter, they have been deprived of all the illustrations and analogies in other classes of animals, of all the advantages to be derived from the wider contemplation of animated nature, and of the marvellous unity of design in the generative process evident throughout the whole series of animated life.

The eyes of physiologists have been directed to find out the mysterious moment when, during impregnation, or soon after that circumstance, the Fallopian tube has grasped the ovary, and drawn into its canal the impregnated ovum, When appearances have favoured the idea of impregnation, the cavity on the surface of the ovary was, of course, regarded as a true corpus luteuni ; but, on the other hand, when there were no grounds for inferring impregnation, such an appearance was called a false corpus luteum.

The barbarous nomenclature in use by physiologists, the same expression being used by different author's in differ 'nt meanings, has been another great means of obscuring this subject. "Graafian vesicles," "ova," are used as if they were different things. Then we have "the corpus luteum," "the true corpus luteum," "the false corpus luteum,"- the one the result of impregnation, the other something as yet not satisfactorily accounted for.

I may as well define what these expres. sions mean, and thus get over the pons asinorum of the subject.

Ovum, corpuscle, Graafian vesicle, are different names applied to those bodies existing in great numbers in the ovary of all females, not only in woman, but in the ovaries of all females where the sexes are apart,-terms, all of them expressive of those oval bodies found so numerous, and periodically, by all females of all animals, discharged from the stroma of the ovary at maturity, and that maturation effected by the female herself, without any influence having been exercised by the male ; in fact, an orum, as here defined, containing a ma. cula germinativa within a vesicula germinativa, and this surrounded by the yolk or nutritive material, adapted for the future development of an embryo, is the elaboration, as far as female influence extends, in prepa. ration for the future being, and waiting only for the influence of the male as a stimulns for its development.

The corpus luteum I define as the nidus in the stroma of the ovary from whence has escaped an ovum. Whether that ovum has been impregnated or not impregnated cannot be manifested by any textural difference in the structure of the nidus itself. The appearances must be, in both cases, identical in nature, or if they differ in any degree the difference must be simply one of intensity. An ovule, impregnated, may in the stroma. of the ovary become more enlarged, more matured, and by having received the male influence, more developed, and thus occasion a vacant space to be produced on the periphery of the ovary, only larger than would be produced by a non-impregnated ovule.

It is true, that when an ovum has arrived at maturity it may not escape from the ovary; it may there become atrophied, and be absorbed, and may then give rise to an appearance somewhat resembling a corpus luteum.

The cicatrix is merely the permanent in

$$
3 \text { H } 2
$$


dication of the previous escape of an ovum, \{ illustrated by extensive inquiry. In illus. and bears the same relation to the corpus tration of the oversight of some, even of our lateum as any other cicatrix would to a most distinguished investigators, with regard wound with tumid edges.

Thus I conclude the results of my own personal experience, and the reflections resulting from them, and thus fulfil the pronise which you long since exacted from me. And here my communication would have had an end, had it not been that, since 1 have communicated these facts and opinions to paper, you have directed my attention to the work of Dr. Power on the subject I have been attempting to illustrate.

I consider myself peculiarly fortunate in having had, by you, so opportunely my attention thus directed; as, although the perusal of this elegantly composed and highly philosophical work deprives me, on the one hand, of any merit $I$ might have claimed, on the score of originality, in the views $I$ have long been attempting to elucidate; yet, on the other hand, I am saved the mortification $I$ must have experienced had $I$, in ignorance of a prior claim to them, developed them as my own.

I have still left me the grateful duty of doing homage to a man, whose writings seem strangely to have fallen into oblivion, and rejoice in being the means of bringing again to the notice of physiologists the claims of a most talented author, and restoring to him that high station as a discoverer which his researches, founded on the comprehensive views and highly philosophical generalisations dereloped in his truly classical essay on this subject, entitle him to occupy.

I feel the more pleasure in paying him this candid tribute of respect from finding how nearly my own personal experience has led me to arrive at conclusions similar to those entertained by him. Iguorant of his essay, I had advanced, step by step, to resulty almost identical with those which Dr. Power, founded by him on much personal experience, as well as extensive and well-digested researches in the writings of ancient as well as modern authors, had so ably and fully illustrated more than twenty years since.

In proof of the neglect in which this admirable work has been placed so long, I may observe that Gendrin, in $1839,{ }^{*}$ publishes, as novel, views identical with those of Dr. Power; and Dr. Willis † alludes to Dr. Power, as having merely loosely mooted the question as "an hypothesis," instead of establishing it as a theory, in an essay, which is a model of inductive reasoning, founded on much personal experience, and

* Traite Philosophique de Medicine Pratique, 1839.

+ Translation of Wagner's Elements of Physiology, London, 1841, PartI., p. 69, in the note. to the fundamental points so long since established by this author, I may cite no less an authority than our distinguished countryman, Dr. Robert Lee, who, in the "Cyclopædia of Medicine," published in 1834, article Diseases of the Ovaria, referring to the investigations of Dr. Power,* as detailed in his work, states them, as does Dr. Willis, to be merely "an hypothesis." Some unac. countable misconception of terns seems to have occurred to Dr. Lee, for whilst combatting Dr. Power's statement, that an ovam passes during menstruation, he singularly enough makes use of the following remarks :-

"That an ovum, by which is usually meant an embryo developed in membranes, does not pass from the ovarium during menstruation, is evident from the fact that an ovum is never formed but as a consequence of impregnation, and that conception does not take place at the menstrual period."

Dr. Power's philosophic mind was not guilty of the supposition that to constitute an ovum it was necessary an embryo should be within it. The term with him is generic, applicable to the ovum unimpregnated, as well as to the ovum impregnated.

I am myself induced to quote from $\mathrm{Dr}$. Power, and select a passage, page 15, where he says, "that in women who have never been impregnated, corpora lutea and cavities, which have been supposed previously to have contained ova, have been detected; whence it may be inferred that in them not only the formation but the extrusion of ova is accomplished without the influence of the male."

It is evident from the above passage that Dr. P. uses the word orum not as confined to express its condition after impregnation, when it contains the embryo, and thus to the limited sense in which it is applied by Dr. Lee, but that it is used by him in the sense in which it is generally received, indicated by its derivation, and rendering it applicable to the product of the ovaries of females in other classes of animals, as well as to those in mammalia,--even to those instances in which extrusion takes place previous to impregnalion, as in most fishes and amphibia,as well as to those instances, as in the human

* Dr. Robert Lee refers to “An Essay on the Periodic Discharge of the Human Female," London, 1832. I have not been able to meet with this essay by itself, but refer to it as published in "Essays on the Female Economy," by Dr. Power, in 1821. Indeed, I understand from the author himself, that no other edition than the one of 1821 is he aware of ever having been published. 
subject and all other mammalia, where im- coloured fibrinous matter. The character of preguation is invariably internal.

Nor is Dr. Power's idea of a corpus Iuteum confined to the appearances left by an ovum afler impregnation only. With him there is no distinction between true and false corpora lutea. He applies the expression to describe the appearances existing after the escape of an orum unimpregnated as well as impregnated. In this position he again widely differs from the most classical authors of the present period. Dr. Burns, Dr. Ramsbotham, Dr. Robert Lee; the writers, in fact, whose works are in the hands of students at the present time, all agree in considering the expression as applicable, truly, only to the phenomena appearing after impregnation.

1 perceive my acute young friend, Dr. Robert Paterson, of Leith, adopts, to the fullest extent, the faith of the hypothesis of Dr. Robert Lee.* He has, however, incurred, in no measured terms, the severe animadversions of that learned lecturer, not for his scepticism in the faith of corpora lutea existing only after impregnation, but for the application of what he considered to be the true principles of that faith to explain appearances in the ovary of a female that came under his observation. This female had been long married, but effete. Some short time previous to her death her matrimonial fidelity was suspected. In one of the ovaries of this woman Dr. Paterson discovered appearances that not only he considered, but that Dr. Allan Thomson and Dr. John Reed also considered, as a true corpus luteum, and, therefore, that this female had experienced impregnation shortly previous to death.

In this controversy Dr. Robert Lee disputes the opinions of these physiologists, commencing his opposition on grounds that, in the first place, in the uterus or Fallopian tubes "no ovum, nor any vestige of an ovum, could be detected," and summing up his strictures by the following passage, "Nobody has come forward with a testimonial in behalf of this coipus luteum, or asserted that he saw two membranes around the coagulum of blood, and a layer of coagulable lymph in the centre, filled with a reddish grey-

* For Dr. R. Lee's opinions vide lectures in the "Medical Gazette" of last year; also his paper on the Corpus Luteum, "Med. Chirurg. Transactions," vol. xxii. In a discussion following the reading of this paper, LANCET, June $\mathbf{2 9}, \mathbf{1 8 3 9}$, in a remark in reply to Dr. Bright, who expressed his anxiety to have the society enlightened with regard to the differences of appearance between a true and false corpus Iuteum, Dr. R. Lee is reported to have said that the false were either larger or smaller than the true, and that the effusion was around the two coats of the corpus luteum. this corpus luteum is, in truth, gone for ever-far more. completely blasted than the reputation of the poor lamp-lighter's murdered wife."

These differences of opinion among men of such reputation as physiologists are to be regretted. They might never recur were terms of a more precise and philosophic character, to be used instead of the expressions "true" and "false corpora lutea," now so generally in use.*

Most probably, this female had lately menstruated, and the appearances observed, and so minutely described by Dr. Paterson, $\uparrow$ were the result of the escape of an ovum unimpregnated, and of course the same in structural character with those appearances that are insisted upon by Dr. R. Lee as indicative of the escape of an ovum impregnated.

But although Dr. Lee in the controversy respecting this female lays much stress on the non-detection of an ovum, yet it would seem he does not always rely on it, for he does not mention its detection, nor, indeed, could any one well expect to find it in the instance where he relates that he found " a perfect corpus luteum in the ovary of a woman who died from inflammation of the uterus soon after the expulsion of a mass of serous cysts or hydatids, as they are called, from its cavity." $\ddagger$ And it may be some consolation to those whose minds are perplexed between true and false corpora lutea, and with the difficulty of distinguishing the difference-a difference some, too, may be inclined to consider to be only a difference without a distinction-to find that Dr. R. Lee, after the enumeration of all the minute points in which he considers them to differ, sums up his remarks by candidly stating that although " corpora lutea, such as have been now described, may be regarded as furnishing the most unequivocal proof of impregnation," yet, he adds, that " it is necessary to know that conception may have taken place, and that the corpus luteum may be so small and so imperfectly formed as to be in a great degree destitute of its genuine and distinctive characters."

I willingly pass, however, from this vague verbal controversy, so humiliating to science, and quote this beautiful passage from $\mathrm{Dr}$. Power:-

"If the prolific stimulus is denied, the ovarian action may be insufficient for the

* This controversy begins in Dr. R. Lee's lecture, as published in the "Medical Gazette" of 1842, No. 7; is carried on in Nos. 11,12 , and 16, and ends in 17, where "Scrutator" has the last word.

$\dagger$ In a series of essays in the " Edinburgh Medical and Surgical Journal," Nos, 142, 145 , and 147.

$\ddagger$ Med. Gazette for 1842, p. 195 . 
necessary detachment of the ovum; in this case it is probable that, as a useless structure, it perishes, loses its connection with the uterine system, becomes an extraneous body, and is, by the process of absorption, removed from the ovarium; or, in some cases, where the constitutional or local actions of the uterine system are excessive, the degree of ovarian action may be sufficient to produce the detachment of the ovum. The corpora lutea found in the virgin ovaria may be regarded as the cicatrices remaining from the ulceration attendaut on this detachinent; and the influence of the excessive ovarian action, it is presumed, will be sufficient to account for the formation of the membranous and decidua-like skins in dysmenorrhoea."

Beautiful and eloquent as is this passage, and expressed with the characteristic modesty of the author, it is one only of the many happily-illustrated views of $\mathbf{D r}$. Power with which I am inclined to differ. From the context of this quotation $I$ infer that the withering of the ovum in the ovary, in the opinion of this author, is the more general rule, not the exception. My experience would induce me to reverse the position, and consider the extrusion of the ovule during menstruation as the general rule, its remanet and atrophy there as the exception.

From this valuable essay I might quote sentence after sentence illustrative of how little we have to add at the present time to the views so satisfactorily developed twenty years since. To enable us to perfect a clear, unbroken, and comprehensive riew of all the interesting and perplexing phenomena of the functions of the ovary and uterus in respect to generation, we have only to take Dr. Power's essay - the first essay in Dr. Power's work entitled "Essays on the Female Economy"-as our text-book.

In fact, to republish it entire would be the best means we could adopt to rescue the subject from the abject condition to which the constant employment of ill-defined terms and worse-examined cases have reduced it, and place the phenomena of human generation once more in harmony with those of the rest of organised beings, and add the only link wanting to establish uniformity in the generative function throughout the whole system of animated nature. I am, my dear Sir, your's very sincerely,

\section{G. F. Girdwood.}

Paddington, Jan, 27, 1843.

To Professor Grant, University College.

THE spinal accessory nerve, arising from the posterior part of the spinal cord, seems to be destined to move the muscles which it supplies, viz., the sterno-mastoid and trapezius, in obedience to sensation, but not to volition,-Prof. Alison.

\section{MISCELLANEOUS CONTRIBUTIONS TO PATHOLOGY AND THERAPEUTICS,}

By James Righard Smyth, M.D., London.

IMPOTENCE AND STERILITY.

The following case we consider a fair, and in a praetical point of view, an instructive example of impotence, which depended for years upon causes chiefly constitutional,causes which consisted, we conceive, more in an imperfect development and ill diathesis of the system, with consequent weak func. tional habits, than in the presence of any distinct disorder's, as in the case of $\mathrm{Mr}$. B., last treated of (page 532).

Mr.J.G.S., aged 2S, of a sluggish leucophlegmatic constitution, and of a melancholic temperament; no obvious emaciation, but vascular and muscular systems generally atonic and soft; no appreciable lesion of respiration or of circulation, but pulse rather languid and animal temperature low ; coun. tenance pale and of rather sad expression; pupils somewhat dilated, and irides de. colourised; alvine and urinary excretions stated to be of a healthy appearance; appetite inordinate; testes of the ordinary size, but softer than natural; epididymi contracted and empty; scrotum and penis lax and elongated. He states that he is at present, and that he has been so for years, subject occasionally to nocturnal seminal emissions of a thin watery character, and that he has never been able to perform the act of sexual intercourse, although he has frequently attempted it, and also that for three or four years after he had arrived at the age of twenty-one he practised the sin of the "trespass of Onan." (Genesis, c. xxxviii., v. 9.) But we cannot do better here than give the patient's own graphic account of his case from an early period :-

" $\mathrm{Sir}$,-According to promise I proceed to lay before you a history of my case, and in so doing I shall trace back further, perhaps, than is necessary, but in this respect you will be the best able to judge. In the first place I would inform you that in early youth, viz., from ten years of age until sixteen, as well as $I$ can recollect, I laboured under a scrofulous state of my constitution; was the subject of venereal desires and nocturnal emissions at fifteen, from which time my health seemed gradually to improve, until the age of eighteen, when I had an attack of inflammatory fever, which left me greatly debilitated. At twenty-one I seemed nearly recovered from my attack of fever, and $m y$ sexual powers appeared to revive; but about that time, while washing myself, I became accidentally acquainted with Onanism, which folly I practised more or less until the age of twenty-five, when I became better acquainted with the laws of my physical constitution, and I have no doubt I should 